Research Article

\title{
A Novel Algorithm for Profit Distribution of Sustainable Development Using E-Commerce Supply Chain
}

\author{
Li Wei (iD) ${ }^{1,2}$ \\ ${ }^{1}$ Business School, Yangzhou Polytechnic Institute, Yangzhou 225000, China \\ ${ }^{2}$ The Logistics Institute-Asia Pacific, National University of Singapore, Singapore \\ Correspondence should be addressed to Li Wei; liw@ypi.edu.cn
}

Received 31 August 2021; Revised 13 September 2021; Accepted 18 September 2021; Published 11 October 2021

Academic Editor: Fazlullah Khan

Copyright (c) $2021 \mathrm{Li}$ Wei. This is an open access article distributed under the Creative Commons Attribution License, which permits unrestricted use, distribution, and reproduction in any medium, provided the original work is properly cited.

E-commerce supply chain actually deals with the acquisition of the raw materials, their timely processing, and on-time delivery to the right place. It deals with a number of processes such as supply and demand, managing order entry, and inventory tracking. Now profit distribution models are actually stochastic models that are used to optimize the gains and profits in a particular business. They actually generate modern time solutions to the existing problems in a sustainable environment. However, in order to solve the problems existing in the traditional profit distribution algorithm of the e-commerce supply chain, such as low distribution accuracy and large time cost, a profit distribution algorithm of the e-commerce supply chain under the concept of sustainable development was designed. It was supported by the concept of sustainable development, and the coefficient of income distribution is calculated according to the equilibrium bidding strategy of supply chain alliance and its members, net present value of income distribution, total investment, minimum expected rate of return on investment, and other parameters. First, calculate the Shapley value of the profit distribution of the power supply chain, and obtain the correction coefficient through the correction matrix, dimensionless processing, and analytic hierarchy process. Use the correction coefficient to correct the Shapley value and the income distribution coefficient to realize the design of the profit distribution algorithm for the power supply chain. The experimental results show that the algorithm has low relative error rate, high precision, and short time cost of profit distribution coefficient calculation.

\section{Introduction}

With the rapid development of the Internet, electronic information, and mobile terminal technology, e-commerce, as an emerging industry, has developed rapidly, bringing many development opportunities and creating a wealth myth [1]. As a result, a large number of enterprises flood into the e-commerce market and participate in the competition as e-commerce enterprises. With the deepening of economic globalization, the market competition among e-commerce enterprises has increasingly reached the white-hot stage, and its competition mode has been transformed from the traditional individual competition to the competition in the whole supply chain of enterprises [2]. Each participant in the e-commerce supply chain is an independent interest claimant driven by the maximization of interests. Each node in the e-commerce supply chain gives priority to its own benefits, transfers operational risks, and grabs excess returns [3]. The intersection of interests of various stakeholders often exists with the game; in the pursuit of self-interest maximization, one party not only can damage the interests of others, but also can destroy the stability of the electricity supply chain structure, by making the supply chain cooperation face uncertainty, hindering the supply chain to maximize the overall interests, and highlighting the profit distribution of supply chain internal contradictions gradually. This contradiction seriously hinders the sustainable development of supply chain cooperation, so it is of great significance to study a profit distribution algorithm of e-commerce supply chain.

To solve the above problems, a lot of research results have emerged in the present stage, such as reference [4] to 
design a kind of electricity supply chain based on cloud gravity method benefit allocation algorithm. The algorithm mainly studies the influence members of the electricity supply chain financing income distribution, the main factors and the level of risk, the degree of information sharing, the effort level, and the audit supervision costs into the cloud gravity method. On this basis, the revenue distribution model is built to complete the design of the profit distribution algorithm of the e-commerce supply chain. However, the time cost of the profit distribution algorithm of the e-commerce supply chain is large and the overall efficiency is low. Reference [5] designs a benefit distribution algorithm of e-commerce supply chain based on block chain technology. Six factors, including resource contribution, status effect, risk taking, additional subsidy, implementation degree, and innovation effort, are proposed to influence benefit distribution, and then a modified Shapley value model is established. At the same time, blockchain technology is applied to solve problems such as mistrust among supply chain members and difficulties in monitoring transaction data. The information transparency and immutability provided by blockchain make the revised profit distribution strategy more fair, credible, and enforceable. However, the calculation of the coefficient of income distribution of the algorithm has relatively low error rate, so the practical application effect is not good.

At this stage, the relevant leaders have stressed in many occasions on the concept of sustainable development, which requires the electricity in lower costs. At the same time, it must pay attention to the scientific methods and cannot rely on the expense of the damage to the ecosystem, in order to realize the coordination of enterprise, society, environment, and sustainable development. This is the concept of sustainable development as the basic requirement of the electric business enterprise. Therefore, this paper designs an e-commerce supply chain benefit distribution algorithm under the concept of sustainable development and verifies the effectiveness of the algorithm through experiments.

\section{Design of Profit Distribution Algorithm for E-Commerce Supply Chain}

The word "benefit" has many different meanings, and even the interpretation of the benefit varies widely in different environments. Other relevant experts and scholars have defined this; that is, interest belongs to the category of social relations in essence, and it is a kind of need in essence, which can satisfy the psychological and behavioral demands of all classes and groups. All groups obtain psychological and behavioral satisfaction to maintain their own survival and development, which can meet the needs of different groups of objects. Profit distribution refers to the fact that, in various cooperative relationships, the participants share their due share from the total income or profits generated by cooperation [6]. The benefit distribution of the supply chain means that each member of the supply chain takes its due share from the total profit or revenue created by the supply chain alliance. Of course, each member of the supply chain should reasonably share the total cost of the supply chain [7].
The profit distribution of supply chain in this paper mainly refers to the profit increased by participating in cooperation. Cooperation is the prerequisite of benefit distribution, and a reasonable benefit distribution scheme is the guarantee of stable cooperative relationship. For supply chain members, joining the supply chain alliance can not only enjoy various shared resources brought by collaboration, but also improve efficiency and reduce costs, so as to gain more benefits [8]. However, combined with the current situation of e-commerce supply chain cooperation, its profit distribution model is often difficult to put into practice technically. Therefore, how to make a reasonable benefit distribution scheme of supply chain has become an imminent problem of supply chain management.

2.1. Calculation of Income Distribution Coefficient. The supply chain alliance and its members distribute the cost and benefit, and the final amount allocated by both parties must not be lower than the basic expectation of each party before it can be accepted by both parties. From the rational man hypothesis in the bargaining theory, maximizing their own benefits is the code of conduct for both parties. In order to gain a beneficial amount of benefits, both parties generally will not easily choose to compromise [9]. In the process of bargaining, both parties take turns to bid. One party makes the first bid, and the other party can reject or accept it. Only when one party's bid is accepted by the other party, the bargaining process ends; that is, both parties reach the distribution amount satisfying their own interests [10]. Suppose that after this process, the equilibrium bidding strategy of supply chain alliance and its members is obtained, which is represented by $P_{c 1}$ and $P_{e 1}^{\prime}$, respectively.

There will be three situations when the size of $P_{c 1}+P_{e 1}^{\prime}$ is compared with the size of revenue cake $\operatorname{NPV}(P)-I(1+R)$, where $\operatorname{NPV}(P)$ represents the net present value of the income distribution, $I$ represents the total investment, and $R$ represents the minimum expected return on investment.

Case 1. $P_{c 1}+P_{e 1}^{\prime}$ is less than cake NPV $(P)-I(1+R)$.

Both the supply chain alliance and its members have a certain understanding of the relevant cost data or benefits, so any party in its first bid, its bidding strategy set, will refer to the data or benefits they have obtained. At this time, the sum of the bidding strategy values of the supply chain alliance and its members in the case of their first bid, $P_{c 1}+P_{e 1}^{\prime}$, is probably less than the total cake [11]. In this way, $I(1+R)+P_{c 1}$ can be defined as the lower limit of the income distribution interval and the upper limit of the new income distribution interval, and a new income distribution interval $\left(I(1+R)+P_{c 1}\right.$, NPV $(P)-$ $P_{e 1}^{\prime}$ ) can be obtained, which is $P_{c 1}+P_{e 1}^{\prime}$, smaller than the original income distribution interval.

Under the new income distribution interval, repeat the above analysis process; that is, distribute the "reduced income cake" again, and a new income distribution interval will be obtained. In Rubenstein's bargaining model [12], the patience factor is introduced; that is, with each income distribution, the reduction of "cake", and the extension of 
time, the patience degree of both the supply chain alliance and its members will decrease, and their discount factor will also decrease continuously [13]. Therefore, the interval of income distribution will accelerate convergence and eventually converge to a certain point theoretically. Assuming that the convergence point is reached after $n$ rounds of bargaining, the formula is as follows:

$$
\begin{aligned}
\operatorname{NPV}(P)-P_{e 1}^{\prime}-P_{e 2}^{\prime}-\cdots-P_{e n}^{\prime}= & I(1+R) \\
& +P_{c 1}+P_{c 2}+\cdots+P_{c n} .
\end{aligned}
$$

Although the convergence point can be achieved theoretically, it is very difficult to achieve the convergence point in reality. Generally speaking, when the ratio of a new income distribution interval to the size of the initial income distribution "cake" is less than a certain value (set as an acceptable precision level of $\sigma$ ) [14], the discounted value of both parties will reach a very low value and both parties will not care much about the unallocated cake. So the two sides will agree on any point in the new range. In other words, after $h$ rounds of income bargaining ( $h$ less than $n$ ), if the new income distribution interval meets the acceptable accuracy level $\sigma$, the two sides of the new income distribution will be considered as required, and the income distribution will reach an agreement. The formula is as follows:

$$
\frac{\left[\operatorname{NPV}(P)-P_{e 1}^{\prime}-P_{e 2}^{\prime}-\cdots-P_{e h}^{\prime}\right]-I R+P_{c 1}+P_{c 2}+\cdots+P_{c h}}{\operatorname{NPV}(P)-I(1+R)} .
$$

When the acceptable accuracy level $\sigma$ is reached, the new income distribution interval is

$$
\left(I(1+R)+P_{c 1}+P_{c 2}+\cdots+P_{c h}, \mathrm{NPV}-P_{e 1}^{\prime}-P_{e 2}^{\prime}-\cdots-P_{e h}^{\prime}\right) .
$$

At this point, the income distribution value points of the supply chain alliance and its members can be selected at any point within this range. It is assumed that the proportion of the benefits of the supply chain alliance from the new interval to the size of the new interval is $\alpha$, where the size of the new interval is

$$
\begin{aligned}
C= & \left(\operatorname{NPV}(P)-P_{e 1}^{\prime}-P_{e 2}^{\prime}-\cdots-P_{e h}^{\prime}\right) \\
& -\left(I(1+R)+\left(P_{c 1}+P_{c 2}+\cdots+P_{c h}\right)\right) .
\end{aligned}
$$

At this time, the supply chain alliance's allocation from the original cake NPV $(P)-I(1+R)$ is calculated as follows:

$$
P_{c}^{*}=\sum_{i=1}^{h} P_{c i}+\alpha C .
$$

Members' allocations from the original cake NPV $(P)-$ $I(1+R)$ were

$$
P_{e}^{*}=\sum_{i=1}^{h} P_{e i}+\alpha C .
$$

At this time, the income distribution strategy is $\left(P_{c}^{*}, P_{e}^{*}\right)$.
Case 2. $P_{c 1}+P_{e 1}^{\prime}$ is equal to cake NPV $(P)-I(1+R)$.

The sum of $P_{c 1}+P_{e 1}^{\prime}$ of the bidding strategy values of the supply chain alliance and its members in the case of the first bid is equal to the total cake NPV $(P)-I(1+R)$. At this point, the supply chain alliance and its members reach the value point agreed by both parties on revenue distribution, that is, reach an agreement on revenue distribution [15]. At this point, the profit distribution value point of both parties is $\mathrm{NPV}(P)-P_{e 1}^{\prime}$ or $I(1+R)+P_{c 1}$, and the profit distribution strategy is $\left(P_{c 1}, P_{e 1}^{\prime}\right)$. But the probability of being exactly equal is very low, and even if it does occur, both parties will share the same amount of revenue cake as in the first case.

Case 3. $P_{c 1}+P_{e 1}^{\prime}$ is greater than cake NPV $(P)-I(1+R)$.

If one or both parties of the supply chain alliance and its members expect to share an unusually large cake from the benefit cake of the dual cost control standard, it is possible that the sum of $P_{c 1}+P_{e 1}^{\prime}$ of the bidding strategy values of the supply chain alliance and its members in the case of their first bid is greater than the total cake NPV $(P)-I(1+R)$. But in fact, both the enterprise and the grass-roots employees have a certain understanding of the size of the total cake and the situation of the other party, so the probability of such a situation is very low. If this happens, both parties will reexamine their own expectations and the expectations of the other party, as well as the size of the total cake, so that the distribution will develop towards the first situation mentioned above [16].

To sum up, the revenue distribution strategy of supply chain alliance and its members for the total bargaining revenue cake $\mathrm{NPV}(P)-I(1+R)$ is $\left(P_{c}^{*}, P_{e}^{*}\right)$, wherein $P_{c}^{*}$ represents the revenue distribution of supply chain alliance and $P_{e}^{*}$ represents the revenue distribution of its members. Thus, it can be seen that the amount allocated in NPV $(P)$ of the supply chain alliance is $S_{c}=I(1+R)+P_{c}^{*}$.

The amount allocated to members from income $\operatorname{NPV}(P)$ was $S_{e}=\mathrm{NPV}(P)-\left[I(1+R)+P_{c}^{*}\right]$. Therefore, under the concept of sustainable development, with supply chain alliance as the distribution subject and members as distribution recipients, the income distribution coefficient is

$$
b=\frac{\operatorname{NPV}(P)-\left[I(1+R)+P_{c}^{*}\right]}{\operatorname{NPV}(P)} .
$$

2.2. Profit Distribution of E-Commerce Supply Chain. Shapley value method is a mathematical method proposed by Shapley LS in 1953 to solve $n$ cooperative game problems. When $n$ people are engaged in a certain economic activity, each form of cooperation combined by several of them will get certain benefits. When the interest activities between people are not antagonistic, the increase of the number of people in the cooperation will not cause the reduction of benefits. In this way, the cooperation of all $n$ people will bring the maximum benefit. Shapley value method is a scheme to allocate the maximum benefit, which is defined as follows.

Let us set $N:\{1,2, \ldots, n\}$ if for any subset $s$ of $N$ (representing any union in the set of $n$ members) 
corresponds to a real-valued function $V(s)$ and satisfies the conditions:

$$
\begin{array}{r}
v(\phi)=0, \\
v\left(s_{1} \cup s_{2}\right) \geq V\left(s_{1}\right)+V\left(s_{2}\right), s_{1} \cap s_{2} \neq \phi .
\end{array}
$$

Suppose $[N, V]$ is the cooperative game of $n$ members, $V$ is the characteristic function of the game, and $V(s)$ is the benefit of $s$ cooperation [17]. Assuming that $X_{i}$ represents the revenue allocated by $i$ members of set $N$ from the maximum cooperative revenue $V(I)$ and $X=$ $\left(X_{1}, X_{2}, X_{3}, \ldots, X_{n}\right)$ represents the collective utilization of the allocation of $n$ members' cooperative game, the conditions for successful cooperation are as follows:

$$
\begin{aligned}
W(|s|) & =\frac{(n-|s|)(|s|-1)}{n}, \\
\sum_{i=1}^{n} X_{i} & =v(I) \\
X_{i} & \geq v(i) .
\end{aligned}
$$

In the formula, $\|s\|$ represents the number of members and $W\|s\|$ represents the weighting factor.

When $\phi(v)=\left(\phi_{1}(v), \phi_{2}(v), \ldots, \phi_{n}(v)\right)$ is remembered as the cooperation quantity, $\phi_{i}(v)$ represents the profit distribution (Shapley value) of the $i^{\text {th }}$ member of the member. The formula is expressed as follows:

$$
\phi_{i}(v)=\sum_{s \in s_{i}} W\left[|s|\left(v(s)-v\left(\frac{s}{i}\right)\right)\right] .
$$

In the formula, $s_{i}$ represents all subsets containing members in the set, $v(s)$ represents the income of subset $s$, and $v(s / i)$ represents the income obtained after removing members from the subset.

Shapley value method is widely used in the practice of cooperative benefits. It does not evenly distribute benefits, but distributes them based on the contribution degree of members in the alliance. Shapley value method is actually the weighted sum of marginal benefits of members [18].

However, the classic Shapley value method has many shortcomings. It regards risk taking, capital investment, and other influencing factors of each node as $1 / n$ and ignores other factors in profit distribution. In the case of unequal risk taking among members, the benefit distribution scheme of Shapley value method should be modified appropriately according to the size of risk taking. Based on the existing research results, this section introduces three influencing factors of risk taking, innovation level, and resource input and revises the benefit distribution scheme of Shapley value method in e-commerce supply chain under the concept of sustainable development.

The method steps to correct Shapley value are as follows.

2.2.1. Modified Matrix and Its Dimensionless Processing. On the basis of Shapley value, the set of cooperative objects is $I=\{1,2, \ldots, n\}$, the set of correction factors is
$J=\{1,2, \ldots, m\}$, the test value of the $j^{\text {th }}$ correction factor corresponding to the $i^{\text {th }}$ cooperative object is $a_{i j}$, and the correction matrix is represented by $A=\left(a_{i j}\right)_{n \times m}$. In order to eliminate the commonness caused by attributes and dimensions among various factors, dimensionless processing is carried out on the data of matrix $A=\left(a_{i j}\right)_{n \times m}$. The processing method is as follows:

$$
b_{i j}=\frac{a_{i j}-\min a_{i j}}{\max a_{j}-\min a_{j}} .
$$

The normalized benefit distribution correction matrix can be obtained; i.e., $B=\left(b_{i j}\right)_{n \times m}$ :

$$
B=\left[\begin{array}{cccc}
b_{11} & b_{12} & \cdots & b_{1 m} \\
b_{21} & b_{22} & \cdots & b_{2 m} \\
\vdots & \vdots & \ddots & \vdots \\
b_{n 1} & b_{n 2} & \cdots & b_{n m}
\end{array}\right] .
$$

\subsubsection{Using Analytic Hierarchy Process to Determine the Weight of the Correction Factor.}

Step 1: the first step is to compare scales. According to the judgment principle of pairwise comparison, the binary comparison method is adopted to assign values to indicators at the same level and rank them according to their importance. The assignment criteria are shown in Table 1. $a_{i j}$ is the result of comparing the importance of index $i$ and index $j$, and $a_{i j}=1 / a_{i j}$ exists.

Hierarchical evaluation criteria for the importance of indicators are shown in Table 1.

Step 2: the second step is to construct the judgment matrix and calculate the weight vector. Let the judgment matrix be

$$
R=\left[\begin{array}{cccc}
r_{11} & r_{12} & \cdots & r_{1 m} \\
r_{21} & r_{22} & \cdots & r_{2 m} \\
\vdots & \vdots & \ddots & \vdots \\
r_{n 1} & r_{n 2} & \cdots & r_{n m}
\end{array}\right] .
$$

The root method was used to obtain the weight vector of each index: normalize each column of vectors, and the results are as follows:

$$
W_{i j}^{\prime}=\frac{a_{i j}}{\sum_{j=1}^{n} a_{i j}} .
$$

The characteristic vector $W$ and the maximum characteristic root $\lambda_{\max }$ were calculated as follows:

$$
\begin{aligned}
W_{i} & =\frac{\sqrt[n]{\prod_{j=1}^{n} W_{i j}^{\prime}}}{\sum_{i=1}^{n} \sqrt[n]{\prod_{j=1}^{n} W_{i j}^{\prime}}}, \\
\lambda_{\max } & =\sum_{i=1}^{n} \frac{(\mathrm{RW})_{i}}{n W_{i}}
\end{aligned}
$$

Step 3: consistency test: since the judgment matrix is subjective and one sided, errors are inevitable. In order 
TABLE 1: Hierarchical evaluation criteria for the importance of indicators.

\begin{tabular}{lc}
\hline Ratio factor & Quantitative values \\
\hline As important & 1 \\
A little important & 3 \\
More important & 5 \\
Highly important & 7 \\
Extremely important & 9 \\
The intermediate value of two adjacent & $2,4,6,8$ \\
judgments & \\
\hline
\end{tabular}

to verify the rationality of weight allocation, a consistency test is needed for the matrix. The formula of the consistency test is

$$
\mathrm{CI}=\frac{\lambda_{\max }-n}{n-1} .
$$

In the formula, $n$ is the matrix order and CI is the consistency test index.

$$
\mathrm{CR}=\frac{\mathrm{CI}}{\mathrm{RI}}
$$

In the formula, RI is the average random consistency index, and the value standard is shown in Table 2. CR is the consistency ratio of the judgment matrix. When $\mathrm{CR}<0.1$, the consistency test requirements are met; otherwise, the weight needs to be adjusted.

\subsubsection{Calculating the Distribution Results of E-Commerce} Supply Chain. The Euclidean distance calculation formula is used to calculate the distance between the evaluation object and the positive ideal point and the negative ideal point. $A^{+}=\left(a_{1}^{+}, a_{2}^{+}, \ldots, a_{n}^{+}\right)$is defined as the distance between the evaluation object and the positive ideal point, and $A^{-}=$ $\left(a_{1}^{-}, a_{2}^{-}, \ldots, a_{n}^{-}\right)$is defined as the distance between the evaluation object and the negative ideal point.

$$
\begin{aligned}
& a_{i}^{+}=\sqrt{\sum_{j=1}^{m} \lambda_{j}\left(b_{i j}-b_{j}^{+}\right)^{2}}, \\
& a_{i}^{-}=\sqrt{\sum_{j=1}^{m} \lambda_{j}\left(b_{i j}-b_{j}^{-}\right)^{2}} .
\end{aligned}
$$

In the formula, $\lambda_{j}$ is the weight of the correction factor $j$, which is obtained through analytic hierarchy process.

If $\beta_{i}$ is defined as the closeness of each evaluation object to the ideal point, then

$$
\beta_{i}=\frac{a_{i}^{-}}{a_{i}^{+}+a_{i}^{-}} .
$$

The above results are normalized and $\gamma_{i}$ is defined as the normalized closeness degree. Then,

$$
\gamma_{i}=\frac{\beta_{i}}{\sum_{i=1}^{n} \beta_{i}} .
$$

TABLE 2: Average random consistency index assignment criteria.

\begin{tabular}{ccccccccccc}
\hline$n$ & 1 & 2 & 3 & 4 & 5 & 6 & 7 & 8 & 9 & 10 \\
\hline RI & 0 & 0 & 0.58 & 0.90 & 1.12 & 1.24 & 1.32 & 1.41 & 1.45 & 1.49 \\
\hline
\end{tabular}

Finally, the correction coefficient $\Delta \gamma_{i}$ is obtained, that is, the difference between normalized closeness degree and average degree. Then,

$$
\Delta \gamma_{i}=\gamma_{i}-\frac{1}{n}
$$

When $\Delta \gamma_{i}>0$, it means that the member's contribution to the total revenue of the supply chain is higher than the average level and should be compensated accordingly. At $\Delta \gamma_{i}=0$, it means that the member's contribution is equal to the average level without compensation or deduction. $\Delta \gamma_{i}<0$ means that the member's contribution to the total revenue of the supply chain is below the average level and the corresponding revenue should be deducted.

The above method can be combined with the income distribution coefficient to optimize; then, the following exists:

$$
\varphi_{i}(v)=\varphi_{i}(v)+\Delta \gamma_{i} \times v(I)+b .
$$

It is necessary to prove whether the modified Shapley value $\varphi_{i}(v)$ meets the necessary conditions for successful cooperation. The proof formula is as follows:

$$
\begin{aligned}
\sum \varphi_{i}^{\prime}(v) & =\sum \varphi_{i}(v)+\sum \Delta \gamma_{i} v(I) \\
& =\sum \varphi_{i}(v)+v(I) \sum \gamma_{i}-\frac{1}{n}=\sum \varphi_{i}(v)=v(I) .
\end{aligned}
$$

Obviously, the modified Shapley value can meet the necessary conditions for successful cooperation. Therefore, this improved method is feasible. Moreover, it is more reasonable to judge the contribution to the total revenue of the supply chain by considering factors such as risk taking, innovation level, and resource input. Therefore, the benefit distribution results of the e-commerce supply chain meet the requirements of all parties under the concept of sustainable development.

So far, the benefit distribution algorithm design of e-commerce supply chain under the concept of sustainable development has been completed.

\section{Experimental Design and Result Analysis}

In order to verify the effectiveness of the profit distribution algorithm of e-commerce supply chain under the concept of sustainable development designed in this paper, a simulation experiment is needed to design the specific experimental scheme as follows.

In order to make the experimental results reflect the real situation, the experiment needs to be carried out in the same environment. The specific experimental environment is shown in Table 3. 
TABLe 3: Experimental environment.

\begin{tabular}{lc}
\hline Configuration & Parameter \\
\hline CPU & Intel (R) Core (TM) i5-9400 \\
Frequency & $2.90 \mathrm{GHz}$ \\
RAM & $16.0 \mathrm{~GB}$ \\
Operating system & Windows 10 \\
Digits & 64 bit \\
Simulation software & MATLAB 7.0 \\
\hline
\end{tabular}

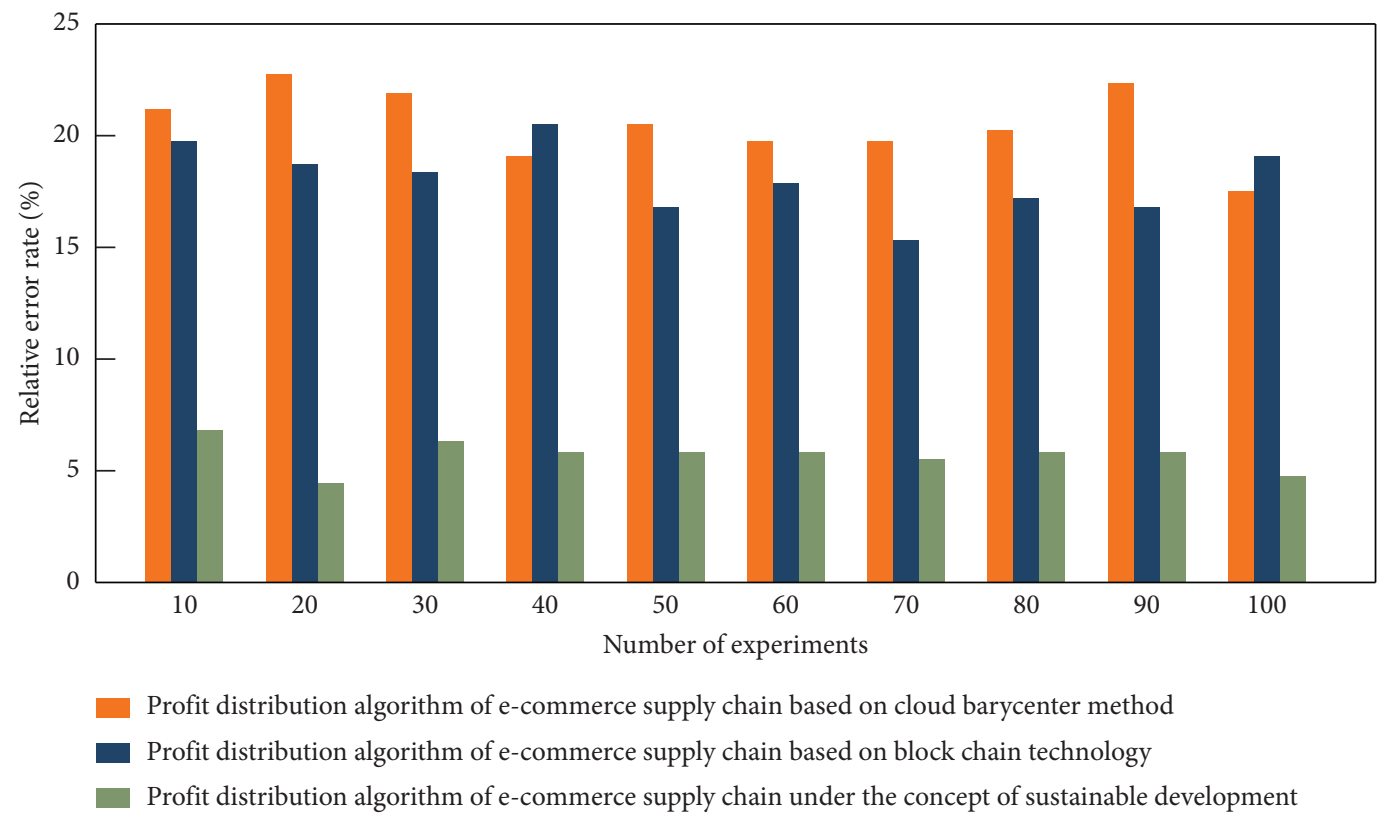

FIgURe 1: Comparison result of relative error rate of calculation of income distribution coefficient.

The experimental data came from a large e-commerce supply chain platform. The background data were taken as the experimental sample data, and the collected data were cleaned and repaired to improve the accuracy of the simulation experiment.

The income distribution coefficient of the relative error rate calculated by the validation electricity supply chain profit distribution algorithm is one of the important indicators. Therefore, first compare the electricity supply chain based on cloud gravity method interest allocation algorithm, based on the technique of block chain electricity supply chain profit allocation algorithm and the concept of sustainable development under the electricity supply chain profit distribution algorithm for calculating the relative error rate and income distribution coefficient. The comparison results are shown in Figure 1.

As shown in Figure 1, with the increase of the number of experiments, the relative error rates of calculation of income distribution coefficient of the three algorithms show different trends. Among them, the relative error rates of calculation of income distribution coefficient of the distribution algorithm based on cloud barycenter method vary between $18.1 \%$ and $22.5 \%$. The relative error rate of income distribution coefficient calculation of the allocation algorithm based on block chain technology varies between $17.2 \%$ and $21.6 \%$, while that of the allocation algorithm based on sustainable development concept varies between $7.1 \%$ and $4.9 \%$, which is the lowest among the three methods. This shows that the algorithm can obtain accurate calculation results of the profit distribution coefficient of the e-commerce supply chain, laying a solid foundation for the subsequent profit distribution of the e-commerce supply chain.

Electricity supply chain profit distribution precision to validate electricity supply chain profit allocation algorithm performance is another important indicator. Therefore, we compared the electricity supply chain based on cloud gravity method interest allocation algorithm, based on the technique of block chain electricity supply chain profit allocation algorithm and the concept of sustainable development under the electricity supply chain profit distribution precision of the algorithm, and the results are as shown in Table 4.

According to the analysis of the data in Table 4, the electricity supply chain based on cloud gravity method interests allocation algorithm of electricity supply chain distribution of average accuracy is $83.5 \%$, and the electricity supply chain based on block chain technology interests allocation algorithm of electricity supply chain distribution of average accuracy is $76.6 \%$, which is the lowest in the three algorithms, and compared with the two types of algorithms, the average accuracy of profit distribution of the e-commerce supply chain based on the allocation algorithm under the concept of sustainable development is $94.8 \%$. It is the 
Table 4: Comparison of distribution accuracy (unit: \%).

\begin{tabular}{lccc}
\hline $\begin{array}{l}\text { Number of } \\
\text { experiments }\end{array}$ & $\begin{array}{c}\text { Profit distribution algorithm of e- } \\
\text { commerce supply chain based on } \\
\text { cloud barycenter method (\%) }\end{array}$ & $\begin{array}{c}\text { Profit distribution algorithm of e- } \\
\text { commerce supply chain based on } \\
\text { block chain technology (\%) }\end{array}$ & $\begin{array}{c}\text { Profit distribution algorithm of e- } \\
\text { commerce supply chain under the } \\
\text { concept of sustainable development (\%) }\end{array}$ \\
\hline 10 & 86.5 & 75.2 & 95.6 \\
20 & 84.2 & 78.4 & 94.8 \\
30 & 81.3 & 74.1 & 96.3 \\
40 & 86.3 & 73.2 & 94.1 \\
50 & 84.2 & 69.6 & 95.2 \\
60 & 81.6 & 85.3 & 93.9 \\
70 & 82.1 & 74.2 & 96.2 \\
80 & 84.7 & 84.1 & 94.7 \\
90 & 80.5 & 75.3 & 93.9 \\
100 & 83.6 & 76.4 & 92.8 \\
Average & 83.5 & 76.6 & 94.8 \\
\hline
\end{tabular}

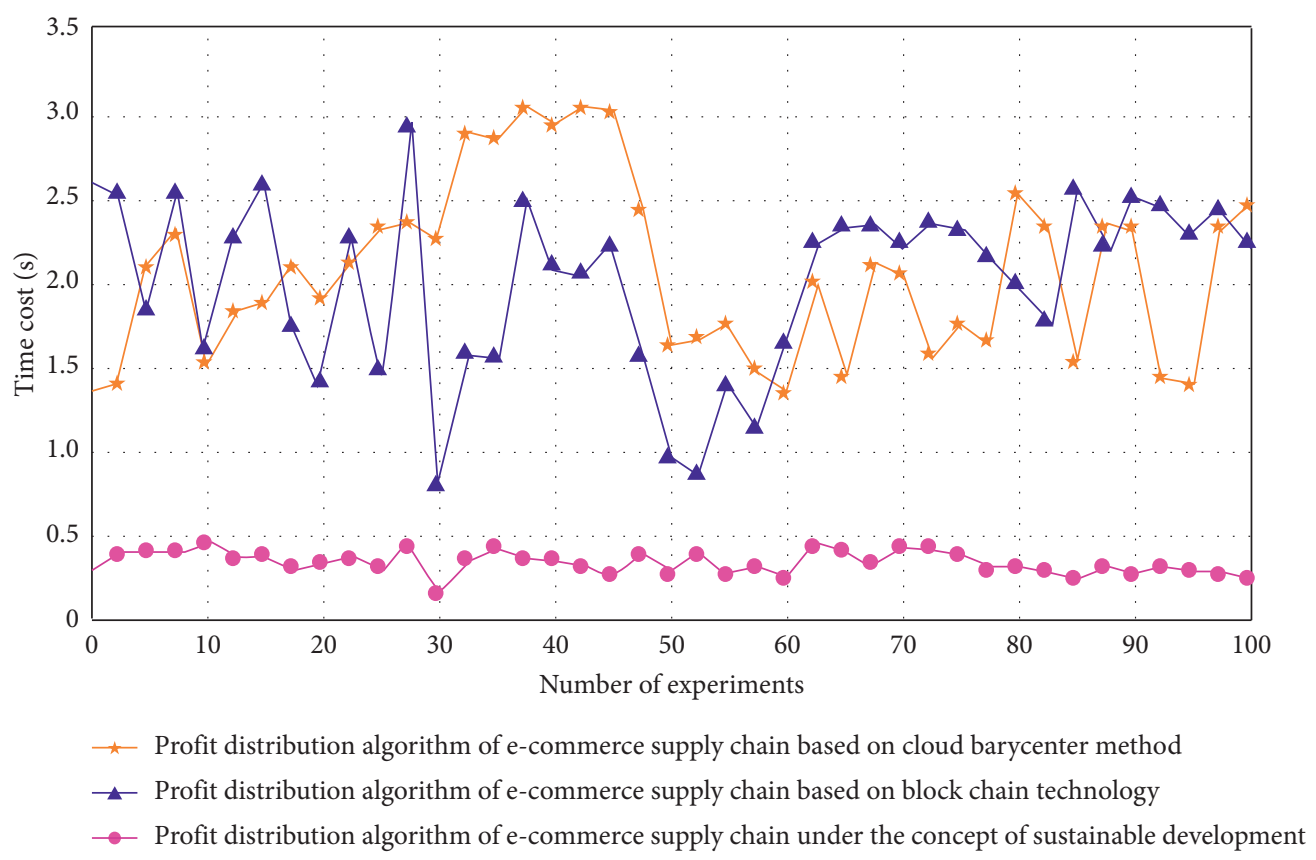

Figure 2: Time cost comparison.

highest among the three algorithms, indicating that the algorithm can achieve accurate interest distribution of e-commerce supply chain and reduce related interest disputes.

Finally, the time cost of the e-commerce supply chain profit distribution algorithm based on cloud barycenter method, the e-commerce supply chain profit distribution algorithm based on block chain technology, and the e-commerce supply chain profit distribution algorithm under the concept of sustainable development are compared, and the comparison results are shown in Figure 2.

By analyzing the data in Figure 2, it can be seen that the time cost of the e-commerce supply chain profit distribution algorithm based on cloud barycenter method changes within the range from $1.41 \mathrm{~s}$ to $3.02 \mathrm{~s}$, and that of the e-commerce supply chain profit distribution algorithm based on block chain technology changes within the range from $0.75 \mathrm{~s}$ to 2.95 . Compared with these two algorithms, under the concept of sustainable development, the time cost of the profit distribution algorithm of the e-commerce supply chain is always below $0.5 \mathrm{~s}$, which is far lower than the profit distribution algorithm of the e-commerce supply chain based on the cloud barycenter method and the profit distribution algorithm of the e-commerce supply chain based on the block chain technology, indicating that the time cost of the algorithm is smaller and the overall efficiency is higher.

\section{Conclusion}

Electronic commerce is considered to be the new engine of economic growth, the network of the impact of a new type of economic activity and opportunity is unprecedented, 
traditional economics is facing the correction, and the old competition rules are unravelling, so a new kind of theory to systematically study and guide the e-commerce is urgently needed. Thus, electricity supply chain arises at the historic moment, but the sharpening contradictions between the relevant members of the supply chain profit distribution are not rational. Therefore, there is a need for electricity supply chain profit allocation algorithm in order to solve these problems, but the traditional algorithm of electricity supply chain profit distribution has various problems such as low accuracy and time cost. As a result, it raised the concept of sustainable development under the electricity supply chain profit allocation algorithm. Experimental results show that the relative error rate after calculation of the income distribution coefficient of this algorithm varies between 7.1\% and $4.9 \%$, the average distribution accuracy is $94.8 \%$, and the time cost is always below $0.5 \mathrm{~s}$. The contributions of this paper are low relative error rate after calculation of the income distribution coefficient, high collocation accuracy, and short time cost which can fully solve the problems existing in the traditional algorithm. It promotes the harmonious and prosperous development of e-commerce supply chains.

\section{Limitations}

The limitations of this paper includes that up till now it can provide a low relative error rate up to $4.9 \%$. However, this can be further decreased with more research and practical approach. The average distribution accuracy ideally should be $100 \%$, but in real time scenarios it may drop a little and obtain a value of $94.8 \%$. So this accuracy can be further improved.

\section{Future Scope}

This profit distribution algorithm based on e-commerce supply chain can be extended up to higher levels as it can further optimize the profits in electronic commerce. This would really help out the economic activities going on.

\section{Data Availability}

The data used to support the findings of this study are available from the corresponding author upon request.

\section{Conflicts of Interest}

The author declares that he has no conflicts of interest.

\section{Acknowledgments}

This work was supported by the Jiangsu Overseas Visiting Scholar Program for University Prominent Young and Middle-Aged Teachers and Presidents: Research Project of Philosophy and Social Sciences in Jiangsu Universities and Research on Jiangsu Logistics Safety Production Management from the Perspective of Sustainable Supply Chain Management (no. 2019sja1859).

\section{References}

[1] A. S. Al-Adwan, M. Alrousan, and A. Al-Soud, "Revealing the black box of shifting from electronic commerce to mobile commerce: the case of Jordan," Journal of Theoretical and Applied Electronic Commerce Research, vol. 14, no. 1, pp. 5167, 2019.

[2] A. Jannah and H. Hassanah, "E-commerce in supply chain," IOP Conference Series: Materials Science and Engineering, vol. 879, no. 1, pp. 12132-12143, 2020.

[3] L. Wang, M. Gao, and Z. Liang, "Application of data envelopment and Internet of things technology for asset value evaluation," Mobile Information Systems, vol. 2021, Article ID 9934090, 8 pages, 2021.

[4] J. X. Du and N. C. Tong, "Research on income distribution of accounts receivable financing based on $\mathrm{B} 2 \mathrm{~B}$ e-commerce platform," Logistics Technology, vol. 42, no. 12, pp. 156-159, 2019.

[5] X. M. Huang and S. Yang, "Research on collaborative benefit distribution strategy of green supply chain-shapley value correction model based on blockchain technology," Journal of Technology Economics and Management, vol. 14, no. 8, pp. 14-19, 2020.

[6] M. Yu, T. Quan, Q. Peng, X. Yu, and L. Liu, “A model-based collaborate filtering algorithm based on stacked AutoEncoder," Neural Computing \& Applications, vol. 5, 2021.

[7] H. Peng, "Research on credit evaluation of financial enterprises based on the genetic backpropagation neural network," Scientific Programming, vol. 2021, Article ID 7745920, 8 pages, 2021.

[8] J.-H. Zhao, D.-L. Zeng, T.-W. Zhou, Y. Hui, and N. Sun, "Analysis of factors affecting the profits of closed-loop supply chain members under different subsidy objects," Computer Systems Science and Engineering, vol. 35, no. 3, pp. 127-139, 2020.

[9] T. V. S. R. K. Prasad, T. Veeraiah, Y. Kiran, K. Srinivas, and C. Srinivas, "Decentralized production-distribution planning in a supply chain: computer experiments," Materials Today: Proceedings, vol. 18, no. 1, pp. A1-A11, 2019.

[10] S. Rao, R. Nilakantan, D. Iyengar, and K. B. Lee, "On the viability of fixing leaky supply chains for the poor through benefit transfers: a call for joint distribution," Journal of Business Logistics, vol. 40, no. 2, pp. 145-160, 2019.

[11] X. Yu, Y. Chu, F. Jiang, Y. Guo, and D. Gong, "SVMs classification based two-side cross domain collaborative filtering by inferring intrinsic user and item features," KnowledgeBased Systems, vol. 141, pp. 80-91, 2018.

[12] R. Isaaks, B. Colby, and A. Dinar, "Empirical application of rubinstein bargaining model in western U.S. Water transactions," Water Economics and Policy, vol. 12, no. 1, pp. 1-25, 2019.

[13] J. Seol and H. I. Son, "Bargaining model-based coverage area subdivision of multiple UAVs in remote sensing," Journal of Biosystems Engineering, vol. 45, no. 4, pp. 133-144, 2020.

[14] Q. Qu, C. Liu, and X. Bao, "E-commerce enterprise supply chain financing risk assessment based on linked data mining and edge computing," Mobile Information Systems, vol. 2021, Article ID 9938325, 19 pages, 2021.

[15] X. Yu, J. Yang, and Z. Xie, "Training SVMs on a bound vectors set based on Fisher projection," Frontiers of Computer Science, vol. 8, no. 5, pp. 793-806, 2014.

[16] T. Ouyang and X. Lu, "Clustering analysis of risk divergence of China government's debts," Scientific Programming, vol. 2021, Article ID 7033597, 9 pages, 2021. 
[17] P. Sun, "Inventory cost control model of fresh products based on Reinforcement Learning," Computer Simulation, vol. 37, no. 8, p. 198, 2020.

[18] D. Sharapov, P. Kattuman, D. Rodriguez, and F. J. Velazquez, "Using the SHAPLEY value approach to variance decomposition in strategy research: diversification, internationalization, and corporate group effects on affiliate profitability," Strategic Management Journal, vol. 42, no. 3, pp. 608-623, 2021. 